\title{
XENIA EFFECT AND HYBRID VIGOUR IN COCONUTS
}

\author{
By \\ K. Satyabalan ${ }^{1}$
}

\begin{abstract}
In coconut the dried endosperin known os the copra is the most important econontic product os it is from the copra, oil is extracted by crushing. To increase the copra content in coconut Haldane (1958) had suggested that it should be possible to compare the size, oil content and other characteristics of the nut borne on the same tree after using pollen from two different pollen parents. The also indicated that the hybrid vigour may possibly show in nuts derivedfrom cross pollination since hybrid vigour in some species is largely due to increased seed weight. If so, it is possible that a mixed plantation may produce a better crop than either of the two breeds when grown alone. Studies on the nut and copra characteristics of Tall $x$ Dwarf hybrids and their reciprocals with their parents in coconut have indicated the importance of selection of pollen parents for producing proinising hybrids which will give better yields and also nuts of better quality and quantity of copra. Hence in copra improvement progrannne by hybridization, selection of parents is of great importance for the production of hybrids which will not only give high yield of nuts and also yield higher outturn of good quality copra. Attempts have been made to identify the best combinersfor the production of high yielding hybrids. Restilts obtained are discussed in this paper.
\end{abstract}

\section{Xenia Effect in Coconut}

In India preliminary observations on the influence of pollen parent on copra content in coconut by Ninan, Pankajakshan and Radhakrishnan (1963) have indicated that the pollinating male parent also exerts some influence on the copra content of the female parent. In their first trial it was observed that Gangabondam, a semi-tall as pollen parent with Laccadive small gave good results on the copra content of Laccadive small indicating that they may be better combiners than the other six cultivars tried as pollen parents. In the same trial it was also observed that the pollen of Kappadam a cultivar which produces large sized nuts gave increased copra indicating the effect of pollen on the copra content of Laccadive small. In the second trial, study of the effect of pollen of eight cultivars on the copra content of Laccadive micro which produces very small nuts had shown that the pollen of Kappadam and Andaman Giant which produce large sized nuts gave an increase of $35 \%$ over that of the local tall as control. This has clearly shown that the pollen of nuts in palms producing large sized nuts had given better xenia effect on the copra content of nuts in palms producing small sized nuts. Thus the influence of pollen on copra content has been observed in both Tall female $X$ Tall male and Tallfemale X Dwarf male combinations. Similar observations in the case of Dwarf female X Tall male combination has been reported from Ivory Coast. In Ivory Coast, Rognon and de Nuce de Lamothe (1983) reported on the influence of Tall pollen on Cameroon Red Dwarf In this study of Dwarf female X Tall male combination, they had reported that the fru it Cameroon Red Dwa f as seed parent fertilized by Tahiti Tall pollen, the copra weight per nut was intermediary to the two parents whereas with West African Tall pollen the copra content per nut obtained was very much greater than that of either of the parents. This indicated that West African Tall was a better combiner with Cameroon Red Dwarf when compared with Tahiti Tall.

\footnotetext{
${ }^{1}$ Ananda Vilas, Opp. Parur Courts, Ernakulam District, Kerala, India
} 


\section{Hybrid Vigour in Coconut}

In India manifestation of hybrid vigour in seedling characters yield of nuts and nut and copra characteristics of West Coast Tall female X Gangabondam male hybrids has been reported and Gangabondam as pollen parent was found to influence the performance of hybrids (Satyabalan, Ratnam and Kunjan 1970). Among the promising hybrids released for general cultivation in Kerala is Labhaganga which is a hybrid between Lahshadweep (Laccadive) Ordinary as female parent and Gangabondam as pollen parent (Anon. 1989). This promising hybrid confirms; the finding reported from the xenia studies by Ninan et al (1963) that Gangabondam as pollen parent gave good results on the copra content of Laccadive small. Tlius Gangabondam is found to be a better combiner with Laccadive for the production of promising hybrids. Based on the results obtained from the xenia studies, Rognon and de Nuce de Larnothe (1983) wished that it will be an achievement if it is possible to link this ability of the varieties to combine to give a large copra in the seed to the productivity of the hybrid arising from that seed. Among the different hybrids released by the Institut de Recherches pour les Huiles et Oleagineux (IRHO) is PB 111 which is a combination between Cameroon Red Dwarf as female parent and West Aftican Tall as pollen parent. In this combination of Dwarf female X Tall male, the xenia effect noted in Cameroon Red Dwarf nut pollinated with West African Tall pollen reflected in the manifestation of hybrid vigour in the hybrid PB 111 (Sangare, de Nuce de Larnothe and Le Saint, 1983). This has indicated that it may be possible to identify the best combiners for the production of promising Dwarf female X Tall male hybrids based on xenia studies.

\section{Crosses Between, Palms Produicing Nuts at Different Sizes in the Tall Variety to Obtain in the Hybrid a Favourable Copra to Husked Nut Ratio by Breeding}

At the Second session of FAO Technical Working Party on Coconut Production, Protection and Processing held in Sri Lanka in 1964, Fremond had suggested to the workers to consider the possibility of combining a large nut size with a favourable copra to husked nut ratio by breeding. Based on the results obtained by them, Ninan et al (1963) had suggested that better crop yields could be raised without additional cost of labour by interplanting such breeds as would give maximum copra content in nuts upon inter-breeding. The data presented, in Table 1 on the performance of the hybrids of Tall X Tall palms producing large, medium and small sized nuts as parents indicate that out of the different hybrid combinations planted, those producing medium and small sized nuts as parents had given more copra outturn than those of the female parents of the hybrids. This observation confirms that the xenia effect observed in the combinations of Laccadive small with the pollen of Kappadam and Andaman Giant cultivars which produce large sized nuts is indicative of the combining ability which is noticed in the manifestation of the hybrid vigour in the nuts of the hybrids involving palms producing small and medium sized nuts, the hybrid palms produced. medium sized nuts which had a favourable ratio of copra to husked nut by weight when compared to those of their fernale parents (Table 1). Such palms producing medium and small sized nuts could be interplanted in plantations to obtairi a higher copra outturn. It is observed that in nature itself such pollination between palms producing small and medium sized nuts takes place as is happening in Laccadive Islands in India. Here it is reported that there is introgression taking place between the palms of Laccadive micro which yields small sized nuts and those of Laccadive Ordinary which yields medium sized nuts resulting in palms of Laccadive, small. Extensive outcrossing between palms of these two cultivars growing side by side have resulted in immediate types which are referred to as Laccadive small or Laccadive medium types. (Jacob and Krishnamoorthy 1981). These observations indicate that it may be possible for the breeder to identify suitable parents for the production of promising hybrids in Tall female X Dwarf male and Dwarf female X Tall male combinations and also select parents based on the size of nuts among the local tails for raising plantations for obtaining a higher copra outturn from them. 


\section{REFERENCES}

ANONYMOUS, 1989 Promising Coconut Cultivars and Hybrids. Tech. Bull. 20 Central Plantation Crops Research Institute. Kasaragod, Kerala, India.

FOOD AND AGRICULTURE ORGANIZATION 1964. Rgp. Second FAO Tech. Wkg. Party Cocon. Prod. Prot. and Processg. 30 Nov to 8 Dec 1964. Colombo, Ceylon. (PL/1964. Colombo, Ceylon, (PL/1964? 11.12).

HALDANE, J. B. S. 1958. Suggestions for research on coconuts. Indian Cocon. J. 12: 1-9

JACOB, P. M. and KRISHNAMOORTHY, B. 1981. Observations on the coconut genepool in Lakshadweep Islands. In Proc. PLACROSYSM IV 1981 pp. 3-8

NINAN, C. A., PANKAJAKSHAN, A.S. and RADHAKRISHNAN, V. 1963. Preliminary observations on the influence of pollen parent on copra content in coconuts (Cocos nucifera L.) Indian Cocon. J. 16:174-178

ROGNON,F and de NUCE de LAMOTHE, M. 1983. Xenia and combining ability in coconut. Coconut Research and Development (ed. N.M. Nayar) Wiley Eastern Ltd., New Delhi. pp. $38-43$

SANGARE, A. de NUCE de LAMOTHE, M. and LE SAINT, J.P. 1983. Promising hybrid coconuts: PB 111 and PB-213 Oleagineux. 38:481-491

SATYABALAN, K., RATNAM, T. C. and KUNJAN, P. V. 1970. Hybrid vigour in nut and copra characters of coconut hybrids. Indian J. agric. Sci. 40: 1088-1093 
Table I. Performance of Parents and Hybrids of Tall Variety Palms Producing Large, Medium and Small Sized Nuts

\begin{tabular}{|c|c|c|c|c|}
\hline $\begin{array}{c}\text { Parents/ } \\
\text { Hybrids }\end{array}$ & $\begin{array}{l}\text { Mean Yield } \\
\text { of nuts per } \\
\text { Palm/annum }\end{array}$ & $\begin{array}{c}\text { Copra } \\
\text { Content } \\
\text { Per nut } \\
\text { (g) } \\
\end{array}$ & $\begin{array}{c}\text { Apprx. } \\
\text { Annual } \\
\text { Copra outturn } \\
(\mathrm{kg}) \\
\end{array}$ & $\begin{array}{c}\text { Copra } \\
\text { To husked } \\
\text { Nut ratio } \\
\% \text { by weight }\end{array}$ \\
\hline \multicolumn{5}{|l|}{ 1. SMALL X MEDIUM COMBINATION } \\
\hline \multicolumn{5}{|l|}{ PARENTS: } \\
\hline Palms producing Small sized nuts & 234 & 73.8 & 17 & 40 \\
\hline Palms producing Medium sized nuts & 121 & 183.2 & 22 & 27 \\
\hline \multicolumn{5}{|l|}{ HYBRIDS } \\
\hline Small $q \mathrm{X} \delta^{\top}$ Medium & 128 & 172.6 & 22 & 29 \\
\hline Medium $+\mathrm{X} \lesssim$ Small & 146 & 182.2 & 27 & 30 \\
\hline \multicolumn{5}{|l|}{ 2. MEDIUM X MEDIUM COMBINATION: } \\
\hline \multicolumn{5}{|l|}{ PARENTS: } \\
\hline Palms producing Medium sized nuts (1) & 137 & 160.3 & 22 & 32 \\
\hline Palms producing Medium sized nuts (2) & 116 & 117.5 & 21 & 32 \\
\hline \multicolumn{5}{|l|}{ HYBRIDS: } \\
\hline Medium (1) $q$ X Medium (2) $\widehat{\partial}$ & 101 & 166.7 & 17 & 30 \\
\hline Medium (1) + , Medium (2) $\hat{\jmath}$ & 125 & 152.9 & 19 & 32 \\
\hline \multicolumn{5}{|l|}{ 3. LARGE X MEDIUM COMBINATION: } \\
\hline \multicolumn{5}{|l|}{ PARENTS: } \\
\hline Palms producing Large sized nuts & 116 & 224.6 & 31 & 34 \\
\hline Palms producing Medium sized nuts & 116 & 117.5 & 21 & 32 \\
\hline \multicolumn{5}{|l|}{ HYBRIDS: } \\
\hline Large ? X $q$ Medium & 106 & 170.2 & 18 & 30 \\
\hline Medium ? X つ̋'Large & 116 & 161.9 & 191 & 28 \\
\hline
\end{tabular}

Small : Palms producing nuts having a copra content of less than $100 \mathrm{~g}$ per nut.

Medium: Palms producing nuts having a copra content between 100 - 200 g per nut.

Large : Palms producing nuts having a copra content of more than $200 \mathrm{~g}$ per nut. 